
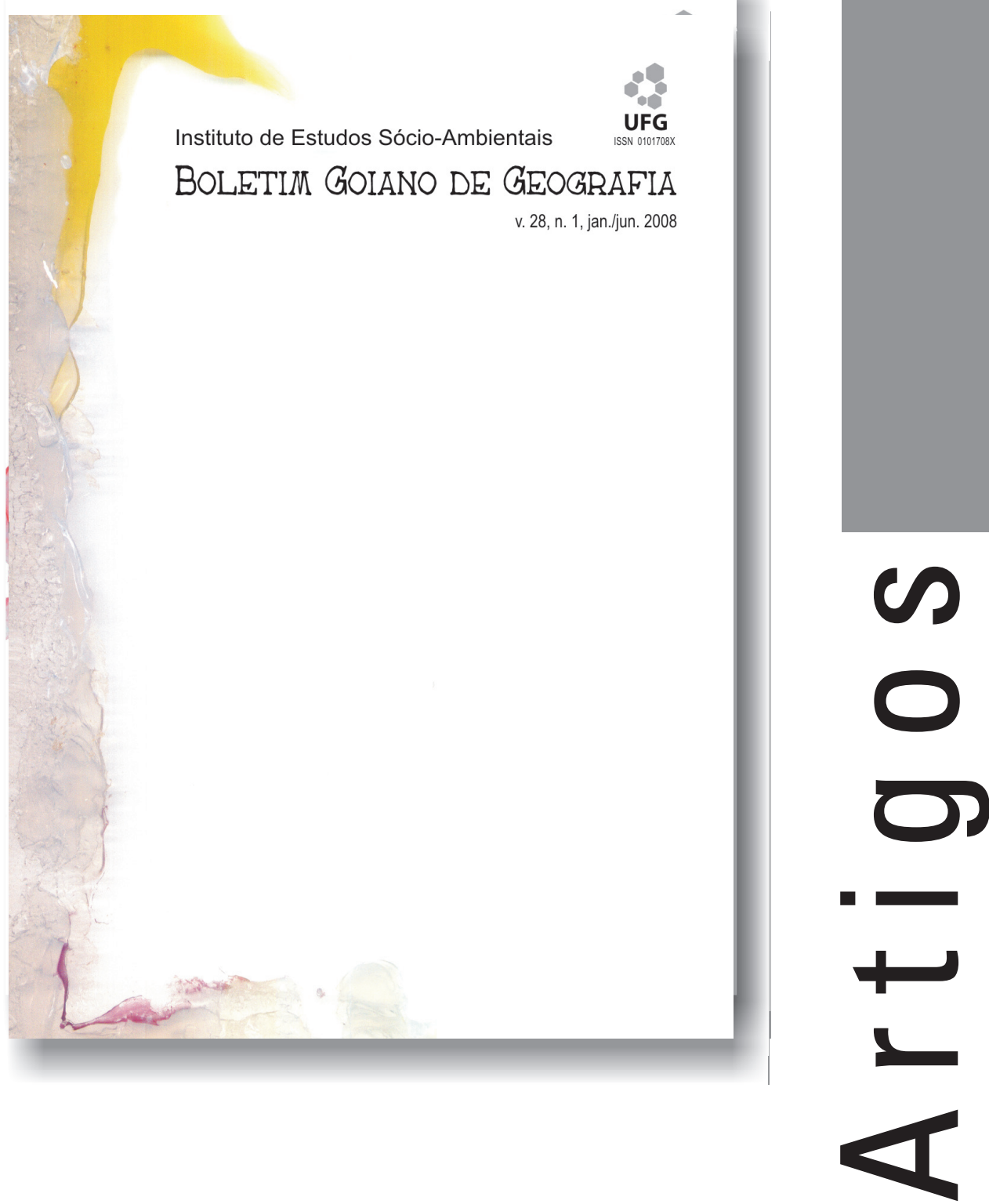


\title{
Relação cidade-campo: da compreensão clássica a sua interpretação no contexto de um assentamento de reforma agrária
}

\author{
Relación ciudad / campo: de la comprensión clásica a su interpretación en el contexto de un \\ asentamiento de reforma agraria
}

Sandro Cristiano de Melo - S.M.E - Goiânia

sandrocristianomelo@bol.com.br

\section{Resumo}

No atual período técnico, entender o rural e 0 urbano, não é algo que se restringe mais a uma cidade e seu campo imediato. As relações possuem uma amplitude maior $\mathrm{e}$ devem ser pensadas no conjunto da totalidade que as integra: na estrutura, na função, na forma e no conteúdo tanto da análise geográfica, bem como de outros campos de investigação científica. 0 debate acadêmico acerca da relação cidade-campo tem cada vez mais exigido uma compreensão de como essa discussão se deu em manuscritos considerados clássicos da discussão agrária. Por outro lado as leituras contemporâneas que as ciências sociais desenvolvem de fenômenos que se instalam nesses espaços exigem um cuidado maior tendo em vista que elementos tanto da cidade quanto do campo se fazem presentes no comportamento social dos seus sujeitos. 0 assentamento de reforma agrária Canudos, no Estado de Goiás pode ser um exemplo dessa fusão de costumes e hábitos os quais foram investigados através da pesquisa 'no sopé da metrópole: implicações da relação cidade-campo na dinâmica sócio-espacial do assentamento Canudos - G0.'

Palavras-chave: cidade-campo; interpretações clássicas e contemporâneas; assentamento de reforma agrária

\section{Resumen}

En el actual periodo técnico, entender el medio rural y el medio urbano no es algo que se limita únicamente a una ciudad y a su entorno inmediato. Las relaciones poseen una amplitud mayor y deben ser pensadas en el conjunto de la totalidad que las integra: en la estructura, en la función, en la forma y en el contenido tanto en el análisis geográfico, como en otros campos de investigación científica. El debate académico sobre la relación ciudad/medio agrario ha exigido cada vez más que se comprenda como surgió esa discusión en los manuscritos que son considerados clásicos de la discusión agraria. En contra partida las lecturas contemporáneas que las ciencias sociales desarrollan sobre los fenómenos que se instalan en esos espacios, exigen un cuidado mayor teniendo en cuenta que elementos tanto de la ciudad como del medio agrario se hacen presentes en el comportamiento social de sus sujetos. El asentamiento de reforma agraria "Canudos" en el Estado de Goiás puede ser un ejemplo de esa fusión de las costumbres, las cuales fueran investigadas a través de la pesquisa: "En el 'sopé' de la metrópoli: implicaciones de relación ciudad/campo en dinámica socio espacial - Canudos-GO".

Palabras-clave: ciudad campo; interpretaciones clásicas y contemporáneas; asentamiento de reforma agraria 


\section{Introdução}

A produção acadêmica atual, em que o controle sobre o tempo de pesquisa, o sentido pragmático do que é feito e para que é feito, assim como a diversificação de trabalhos feitos pelo crescimento da pós-graduação, tem sufocado a leitura do que se convencionou chamar de "clássicos", não apenas em geografia, mas em outros campos de saber das ciências humanas.

Recuperar a interpretação clássica de fenômenos contemporâneos, por outro lado, instala-se como vetor indispensável para cunhar a análise de objetos do atual período, dando certa noção de origem e sentido. E, além disso, contribui para que se dê consistência e lucidez ao discurso que se faz, uma vez que se encontram presentes na leitura clássica os motes que fundaram um tipo de interpretação e então passam a balizar interpretações, de fenômenos atuais ligados a determinadas temáticas.

Nesse sentido, com esse breve artigo desejamos levantar algumas questões que ilustrem o debate da relação cidade-campo por meio de interpretações clássicas, haja vista que, no período atual, as discussões, debates, análises, pesquisas que abordam a relação cidade-campo cada vez mais se mostram presentes, em que ao se abordar a temática de um espaço como o campo invariavelmente se aproxima de elementos e temáticas que margeiam ou se adentram a cidade. As idéias que aqui serão mostradas partiram de uma reflexão maior, e dessa proximidade anteriormente citada, através de nossa pesquisa de doutorado, a qual resultou na tese 'No sopé da metrópole: implicações da relação cidade-campo na dinâmica socioespacial do Assentamento Canudos - GO’1 , porém, apresentaremos apenas uma parcela da idéia e do debate campo-cidade dialogando com o objeto de nosso estudo.

Inicialmente, é importante que levantemos o problema: quais são os pontos definidores da relação cidade-campo mediante uma leitura clássica? A pergunta pode ser definida em outros termos: como era a relação cidadecampo na troca simples ou concorrencial do capitalismo? Ainda no quesito questionamento, uma pergunta de cunho metodológico se impõe: é possível compreender a complexidade atual da relação cidade-campo sem ler recorre à leitura clássica? No que se pretende, traçaremos alguns pontos que explicitam a estrutura clássica da relação cidade-campo, buscando, ao mesmo tempo, compreender como esse debate se coloca nas demandas atuais, especialmente correlacionando-o com os movimentos sociais ligados à luta no campo.

Elementos essenciais da compreensão clássica da relação cidadecampo. 
Ao tomar a idéia desenvolvida por Santos (1978, 1982, 1988, 1996), Moreira (1987), Soja (1993) e outros autores que afirmam que o espaço é, necessariamente, submetido à lei da totalidade histórica, a partir de diferencialidades que se combinam, parte-se da idéia de que tanto a cidade como o campo são construções históricas, por isso há de se entender que em cada momento da história da sociedade apresenta-se conceitos e especificidades dadas ao lugar. Nesse sentido, vale a observação que Moreira (2005) faz sobre a evolução geral da relação cidade e campo, ao longo da história enquanto modo de organização espacial das sociedades, destacando-se três formas dessa relação: cidade e campo numa sociedade de cultura rural; cidade e campo numa cultura de divisão territorial de trabalho; e cidade e campo numa sociedade de cultura urbana.

Ao compreender que a totalidade histórica é expressivamente enunciada no modo de produção, surge aqui um ponto: o modo de produção capitalista nasceu e se desenvolveu em espaços e tempos diferenciados, e a sua atuação foi e é condicionada pelas especificidades de cada espaço. Não é à-toa que uma vertente de estudiosos do nascimento do capitalismo defende que o seu surgimento é explicado a partir do desenvolvimento de ações sociais e atividades comerciais ligadas à cidade, ou seja, a cidade capitalista deu origem ao modo de produção capitalista.

Isso quer dizer que o campo pré-capitalista, ou o campo posterior ao capitalismo era o espaço de conteúdo social que representava uma sociedade em que, por exemplo, a ação direta do mercado, a rotação da mercadoria, o dinheiro como equivalente geral, a consagração do trabalho assalariado, a fragmentação e a diferenciação entre a esfera da produção e do consumo elementos do capitalismo - não poderiam se efetivar.

O campo à frente de uma sociedade revolucionária - o capitalismo que derrubaria o ancien regime - era o atraso porque espacializava um conteúdo social baseado no trabalho complementar e familiar, no uso de produtos para a sobrevivência, na pouca ou quase nenhuma possibilidade de mobilidade social, no sentido apenas usual e funcional da moeda e, especialmente, definindo apenas as trocas simples. Sobre o contexto apresentado até então, Kautsky (1980:29) observa o seguinte:

A família do camponês da Idade Média constituía uma sociedade econômica bastando-se inteiramente, ou quase inteiramente, a si mesma, uma sociedade que não apenas produzia os seus gêneros alimentícios, mas também construía a sua casa, os seus móveis e utensílios domésticos; fabricava mesmo a maior parte das ferramentas grosseiras com que curtia peles, preparava o linho e a 
lã, confeccionava as suas roupas, etc. O camponês ia certamente ao mercado, mas unicamente para vender o sobejo do que produzia, e apenas comprava o supérfluo, exceto o ferro que empregava, alias na menor quantidade possível. Do resultado do mercado poderiam depender a sua abastança e o seu luxo, mas nunca a sua existência.

Na troca simples, a coordenação do sentido social da cidade residia no campo, pois cabia a ele congregar funções, atividades e formas que dessem vida a esse tipo de sociedade. Implementar a troca capitalista, ou chegar em nível de uma economia-do-lucro, significava alterar a relação cidade-campo, mexendo em seus conteúdos sociais. Mas o autor supracitado corrobora ainda com sua interpretação sobre o que já estaria acontecendo, a "dissolução da pequena indústria camponesa”, a partir do momento que a indústria essencialmente urbana e o comércio estariam determinando.

No seio da família rural só era possível uma fraca divisão de trabalho, que não ia além da divisão entre homens e mulheres. Não admira, pois, que a indústria urbana tenha ultrapassado a indústria doméstica dos camponeses e que tenha criado para estes as ferramentas e os instrumentos que a segunda estava longe de poder fornecer tão perfeitos, que às vezes mesmo não podia fabricar. Mas o desenvolvimento da indústria e do comércio produziu também no meio urbano novas necessidades, as quais, da mesma maneira que os instrumento novos, aperfeiçoados, penetravam no meio agrícola de maneira tanto mais rápida e tanto mais irresistível quanto mais ativas se tornavam as relações entre a cidade e o campo. KAUTSKY (idem.).

Essa transposição, conforme Williams (1989), teria que obrigar o campo e os produtores rurais, camponeses, arrendatários a entrarem na órbita do lucro, sendo compelidos a desenvolver inovações técnicas que culminariam em estabelecer mudanças substanciais no espaço. Adotar novas técnicas de cultivo incidia na reinterpretação do sentido da propriedade e da terra. Assim como assinalava que o setor que as gerava - e o espaço que poderia concebê-las mais eficientemente - juntando conhecimentos, oficiais, artesãos e adiantando os estágios de manufatura para a posterior maquinofatura, seria necessariamente a cidade. Daí a tese de que o capitalismo é uma invenção urbana, pois a cidade foi a realidade espacial que possibilitou a efetivação da troca concorrencial no século XVIII.

Ainda que essa tese possa ser contestada em casos específicos, o que se coloca é que a constituição do modo de produção capitalista põe em marcha a necessidade de reorganizar campo e cidade para espacializar as funções do capital e do mercado. Nessa transposição de funções, o que se viu foi 
a expulsão de camponeses pelo regime dos cercamentos, que davam a eles apenas uma direção: as cidades. Nelas, o amontoado de trabalhadores estaria fadado a entrar nas oficinas e mais tarde nas indústrias modernas, como se pode observar nos argumentos elaborados por Moreira (1985:28/9).

\begin{abstract}
A subsunção formal é o momento histórico da hegemonização indireta do capital sobre a sociedade, dado a forma principal de capital ser a do capital mercantil e este realizar suas ações através da esfera da circulação. O capital mercantil subordina (subsume) ao circuito do mercado as formas sociais pré-capitalistas existentes, sem alterá-las em sua natureza. A subsunção real é o momento consecutivo, em que a hegemonização se faz pela via direta da absorção da esfera da produção pela forma principal de capital emergente, o capital industrial, por meio da qual subverte as formas sociais até então não incorporadas ao circuito mercantil capitalista, tornando-as capitalistas no ato da incorporação. Antes, o capital controla a esfera da produção através da esfera da circulação. A seguir, o capital mercantil se transforma em capital produtivo e estabelece o controle da esfera da produção. No primeiro momento, a divisão técnica do trabalho é mínima, resumindo-se o capital à forma mercantil e usurária. No segundo, abre-se o leque da divisão técnica do trabalho, e o capital assume todas as suas formas históricas.
\end{abstract}

Esse processo de mudança do campo e da cidade, ligado ao surgimento e à consolidação do modo de produção capitalista, além de produção, mercado, dinheiro, técnica, levava para o campo um outro sentido da propriedade: o lucro. Isso fazia também com que se dispusesse de novas tramas de uso, de novos meios de produzir, e de outro sentido de explorar os trabalhadores da terra. A mudança da cidade arrastava o campo para a mudança do seu conteúdo. Dessa maneira, era importante que as mudanças no campo instituíssem um novo ordenamento social. Assim é que a destruição dos signos da tradição, o desrespeito às leis, o uso direto e consentido da violência, a pilhagem e o roubo de terra, a pressão do Estado, a polícia, os homens já enriquecidos, culminava com o arruinamento das propriedades e das aldeias.

A reboque disso, a cidade ia se equipando, se transformando, se organizando no sentido de sua forma, da estruturação do poder, da função de atividades para ser o lugar de empreendimento da troca concorrencial. Do nascimento da sociedade burguesa nascia também uma cidade burguesa. A força do mercado nesta sociedade teria um correspondente: a cidade do mercado. Rodrigues (2003:23) sintetiza o raciocínio que foi desenvolvido:

Ao se tornar um meio de produção para o mercado e uma mercadoria ao mesmo tempo, a terra adquire características capitalistas de um setor suplementar da 
indústria. Assim, à medida que o capital penetra no meio rural, transforma o sistema de produção atribuindo um novo caráter à propriedade. A ampliação das relações entre cidade e campo acelera o desenvolvimento da indústria e do comércio. Neste sentido, o intercâmbio, tanto de produtos como de idéias, leva a integração progressiva do campo com a cidade.

O debate clássico da "penetração do capitalismo no campo" demonstra, tal como foi recuperado pelo autor mencionado, a idéia de que o aumento da dependência da população rural pela cidade, impelia a transferência de recursos do campo para a cidade. Aqui entra, por exemplo, a alusão de Kautsky (op. cit.), assegurando que o comerciante seria o autor que, neste contexto, intermediaria a relação entre o campo e a cidade. Posto de outra forma, Moreira (idem.) aponta isso da seguinte maneira:

Tem se a aliança de classes cidade-campo fazendo a relação cidade-campo constituir-se o nexo axial das configurações da construção da história. Por conseguinte, o nexo axial da produção/organização do espaço, e para cuja efetividade se voltam as funções de disciplinarização/ordenação desse espaço.

O aumento da produção na cidade e os novos tipos de produtos movidos pela lógica de lucro abriam uma fenda no campo, no sentido ou de inferiorizá-lo ou obrigá-lo a se relacionar com o mercado. Vê se aí, não apenas essa dependência imposta, mas a dificuldade de autonomia do campo, pois a sua indústria doméstica não dava conta de competir com a indústria urbana.

Ainda que não nos caiba imiscuir-se nas especificidades da forma urbana, do século XVII até o século XIX essa cidade passa por uma metamorfose em todos os seus fixos e fluxos, da mesma maneira que vê alterado todo o seu esquadrinhamento. O nascimento da rua de 90 graus, a formação dos 'quartier' ou bairros, a separação de bairros pobres e ricos, a definição da morfologia a partir das instituições de poder, o isolamento, a prisão, a separação de sujeitos inapropriados para as atividades do novo estatuto social, a afirmação da técnica em seus meandros, do mesmo modo que a substituição lenta, mas gradativa das novas instituições de comando frente às instituições da tradição, opera a essencialidade da cidade burguesa: servir ao regime de acumulação; ser o lócus da produção, da circulação e do consumo; ir aos poucos arrebatando mão-de-obra e dispondo-as nas sarjetas a partir da diferença de classes.

É essa realidade que faz com que os estudiosos clássicos do campo - Kautsky (1980) e Lênin (1945) - reconheçam que o seu modelo de interpre- 
tação deveria ter um anseio totalizante, ter uma conotação política e integrar campo e cidade.

Lênin (op.cit.) é enfático no sentido de introduzir a reflexão a partir do conflito de classe entre proprietários e despossuídos. Ao colocar dessa maneira, a solução cabal, última e necessária seria a revolução socialista. O sentido político de sua leitura acaba por não reconhecer elementos específicos da tradição camponesa e do campo. Decorre desse debate outra chave: se haveria ou não, com a evolução do capitalismo, a extinção da pequena propriedade, especialmente a gerida pelo trabalho familiar.

Chayanov (1985), com os seus estudos enfocando "a produção do sistema econômico camponês”, defende uma pluralidade de formas sociais que dão especificidade ao campo e resistência ao sistema produtivo capitalista, mas que não deixa de ter uma relação de subordinação.

Essa frente de análise abre, atualmente, portas para se incluir na apreciação abordagens não apenas economicistas. Ao introduzir elementos da especificidade camponesa, como modo de vida, cultura, subjetividade, saberes, simbolização, vivência, relação com a natureza entre outros, pode alavancar novos meios de pensar as lutas e a organização do poder.

Resulta da análise da relação cidade-campo na emergência da sociedade burguesa moderna alguns vetores. Primeiramente, os de campo analítico: uma análise que prima pela noção de totalidade social e histórica não pode separar campo e cidade; embora um não se misture ao outro. E há entre ambos não apenas convergência, adaptação histórica, mas interferências ativas em diversos campos do tecido social.

Referendar a cidade e o campo como espaços historicamente constituídos, impõe afirmar que a sua análise exige uma periodização, ou a formação de um princípio: pode se pensar o campo e a cidade de cada tipo de acumulação e, inserir nesse tipo, outras variáveis de outros campos, como por exemplo, os culturais. Sendo assim, a relação cidade-campo atual tem uma configuração própria, apresenta, portanto, contradições sociais desse período, possibilidades atuais.

É importante que se atente para outro vetor fundamental da análise geográfica: cidade e campo são realidades espaciais que se diferenciam a partir da escala, da posição, da localização, dos fundamentos físico-territoriais, das relações de poder, do conteúdo demográfico, cultural etc. Essas variáveis incidem em aspectos como oferta de trabalho, possibilidade de inserção social em instituições de formação, relação com outros lugares, produção da renda fundiária, entre outros. Para que possamos ter uma compreensão atual que 
dialogue com o que fora apontado, apresentaremos a seguir algumas reflexões que se edificaram através de uma pesquisa com um assentamento rural relativamente próximo da capital do Estado de Goiás.

\section{Cidade/campo no contexto de um assentamento de reforma agrária 'vinculado' a uma metrópole}

Um caráter mais empírico acerca do que estamos apontando, acerca do entendimento da problemática da relação cidade-campo pode ser 'visualizado' ao se analisar de forma breve o assentamento, de reforma agrária Canudos que dista-se a menos de $60 \mathrm{~km}$ de Goiânia. Este assentamento organizado pelo Movimento dos Trabalhadores Rurais Sem Terra - MST, está radicado no sopé da metrópole goiana, tendo em vista que o mesmo abrange três municípios goianos, em que um deles integra a Região Metropolitana de Goiânia - RMG.

Um ponto de consenso é o de que cada assentamento rural traz em si características da sua condição socioespacial, assim as respostas a essas indagações só podem ser analisadas na particularidade de cada realidade, o que, neste caso de modo especial, nos direciona a olhar o Assentamento Canudos no contexto de uma relação campo-cidade que vai além de sua aproximação com a sede urbana dos municípios de Palmeiras de Goiás, Campestre, Guapó e Cezarina (Ver figura 01 - próxima página).

Além dos condicionantes de ordem física, como a estrutura pedológica e a morfológica, os quais não vamos nos deter, mas que é importante relatar que são propícios ao desenvolvimento agrícola de Canudos, há também na sua localização um conjunto de especificidades que não se encontram em assentamentos mais isolados e distantes de grandes áreas urbanas. Nesse sentido, dado à circunstância espacial de sua proximidade com Goiânia, apresenta um conjunto de contradições e também de possibilidades na relação-cidade campo.

Primeiramente, temos que ter claro o que estamos chamando de relação campo-cidade, e como ela se expressa no assentamento Canudos. Isso nos remete a uma compreensão que fuja da vala comum de se pensar apenas na distinção fisionômica da cidade e do campo, este, sendo visto apenas como o fornecedor de gêneros agrícolas, lugar do atraso, do natural, da alienação do trabalhador, enquanto que aquele seria o espaço do progresso, lugar privilegiado do consumo, lugar da política, da indústria, da modernização, da técnica. 


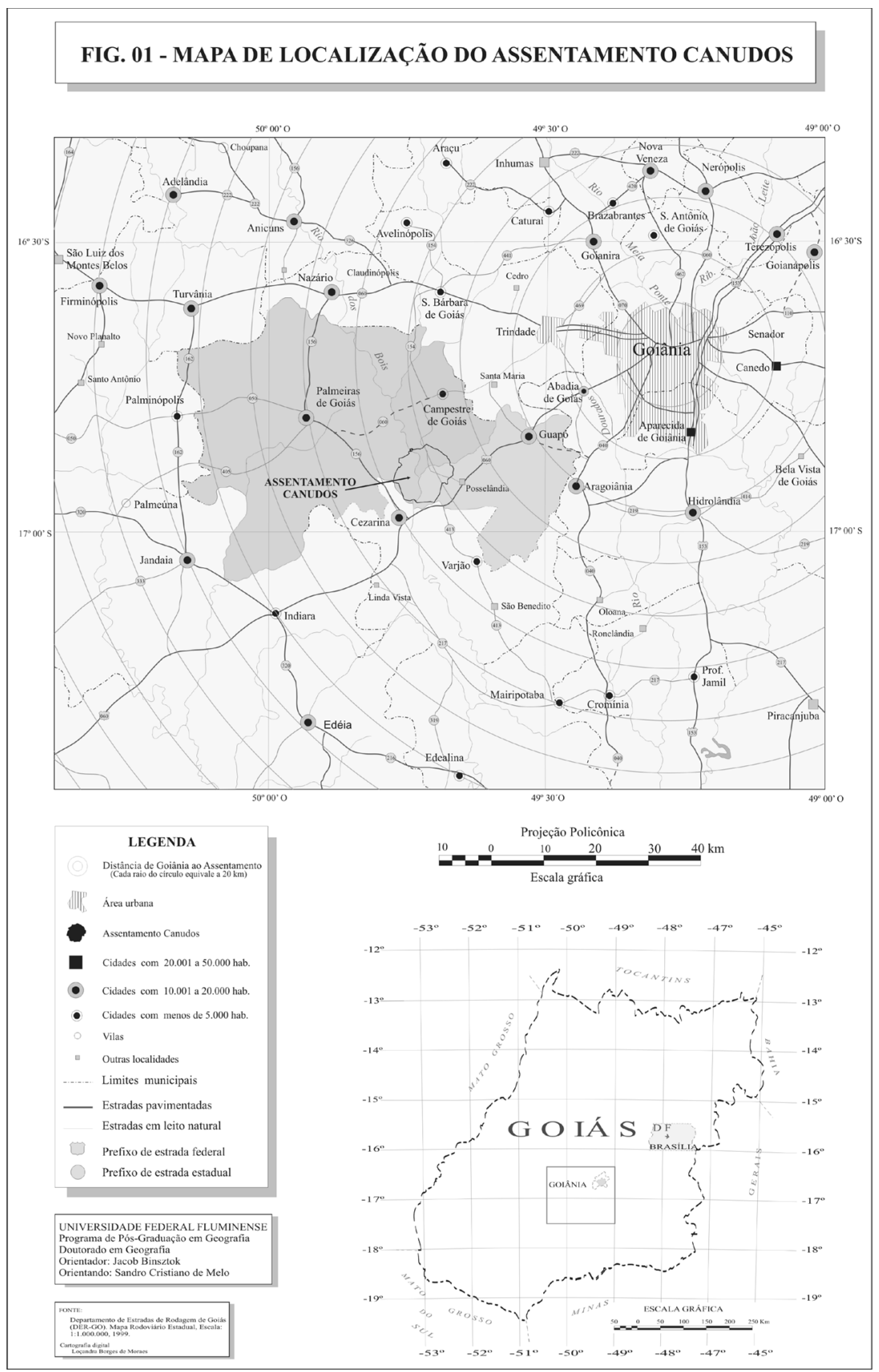


Nossa perspectiva em pensar a afinidade campo-cidade presentes em Canudos, aproxima e separa essa relação por meio de uma perspectiva dialética, tal qual referendam Alentejano (2003), Marques (2004) e também em Lefebvre (2001), em que este argumenta que:

A relação cidade-campo mudou profundamente no decorrer do tempo histórico, segundo as épocas e os modos de produção: ora foi profundamente conflitante, ora mais pacífica e perto de uma associação. Mais ainda, numa mesma época manifestam-se relações bem diferentes (...). (Lefebvre 2001:68)

Na realidade, o quadro apresentado da relação cidade-campo em tempos atuais, deve se reorientar, dando um novo vigor a compreensão que se tinha do isolamento do rural e do urbano durante um longo período, mas que na verdade sempre estiveram relacionados, com maior ou menor intensidade como apontou Lefebvre (idem.), mas de alguma maneira ligados, como bem apresenta Marques (2004:)

O rural e o urbano são partes constitutivas de uma totalidade que se forma na diversidade. Assim, o caminho para se pensar a ruralidade deve partir da análise do significado da relação cidade-campo numa perspectiva dialética. O que implica nos dias de hoje, entre outras coisas, reconhecer que este significado nem sempre pode ser apreendido a partir do contexto social imediato, podendo se referir a escalas mais amplas.

Não se pretende aqui dizer que não há diferença entre campo e cidade, o contrário disso se coloca como real, mas também se deve considerar, como já fora exposto, que existe uma necessidade de entendimento do conteúdo e sentido da relação cidade-campo no período atual, mas que se complementa com o que diz Carlos (2004), para que se possa desvendar como isso se arrola em Canudos.

Há no mundo moderno uma profunda transformação nas relações cidade/campo, apontando a necessidade de desvendamento do conteúdo e sentido destas transformações, centrando a análise no momento e movimento da reprodução da sociedade hoje, saída da história da industrialização, tornando imperativo a necessidade de atualizar a relação cidade/campo no mundo moderno (...).

A cidade e campo se diferenciam pelo conteúdo das relações sociais neles contidos e estas, hoje, ganham conteúdo em sua articulação com a construção da sociedade urbana, não transformando o campo em cidade, mas articulando-o ao urbano de um 'outro modo', redefinindo o conteúdo da contradição cidade/ campo, bem como aquilo que lhes une: este é o desafio da análise (...). Carlos (2004:08/09). Grifos da autora. 
É nesta direção que nossa análise sobre Canudos caminha, tendo em vista que sua organização socioterritorial se envolveu com conteúdos do campo e da cidade, algo que vem sendo gestado nas estratégias do MST no sentido da massificação de trabalhadores, mas que, estrategicamente, também usa a cidade como palco de luta política pela reforma agrária. A lógica disso é que parte dos assentamentos de reforma agrária não rompe suas relações com a cidade; não que isso tenha que acontecer como regra, mas as necessidades que são apresentadas ao cotidiano das famílias assentadas, muitas vezes as colocam reféns da estrutura urbana.

Diante do que fora argumentado, observou-se que o assentamento Canudos, além de ter por princípio da necessidade de sua constituição elementos de conteúdo agrário, possui também independência na formulação do seu conteúdo político, isto é, existe junto aos assentados uma leitura das necessidades de ação no espaço do assentamento, mas há também o entendimento por parte de um bom número de seus correspondentes da obrigação de se articularem com as demandas externas ao seu território.

Isto significa entender que o assentamento não pode se isolar como uma ilha, daí, se relacionar com o externo, numa escala próxima local, o que neste caso seria a sua vizinhança também agrária, mas ao mesmo tempo com as cidades circunvizinhas de Palmeiras, Guapó, Cezarina e Campestre. Entretanto, a lógica de sua articulação extrapolou essa escala, estendendo-se a outras, como no caso do município de Varjão - vizinho a Guapó - e chegando também a Goiânia e sua região metropolitana.

Essa articulação já nasceu durante as fases primárias de Canudos, à época ainda do acampamento, mas que continua até sua fase atual alternando-se em momentos de maior ou menor intensidade. Além disso, embora $64,4 \%$ dos assentados sejam de origem goiana, o restante, 35,6\%, mesmo apresentando as mais variadas origens, já morava em Goiás. Observa-se ainda que um número expressivo de pessoas que foi para Canudos, partiu de cidades do interior do Estado, ou da Região Metropolitana de Goiânia, totalizando assim, mais de $60 \%$ partindo de áreas urbanas em direção a Canudos.

Um instrumento que colabora para uma maior clareza ao que estamos expondo, são os dados da tabela 01 . O assentamento, além de estar próximo a Goiânia, teve na capital e nos municípios de sua região metropolitana o grande peso de sua composição. 
Tabela 01 - Origem de moradia dos titulares de lotes de Canudos antes de se tornarem assentados.

\begin{tabular}{|c|c|c|}
\hline Origem & $\mathrm{N}^{\circ}$ de Titulares & $\mathrm{N}^{\circ}$ em \% \\
\hline Meio Urbano & 173 & 63,1 \\
\hline Meio Rural & 101 & 36,9 \\
\hline Total & 274 & 100 \\
\hline & & \\
\hline Municípios da R. M. G. exceto a capital & 30 & 10,94 \\
\hline Goiânia & 62 & 22,62 \\
\hline Outras localidades urbanas em Goiás & 81 & 29,56 \\
\hline Total & 173 & 63,1 \\
\hline Outros Estados & 9 & 3,28 \\
\hline
\end{tabular}

Fonte - Dados gerados a partir de consultas nos questionários respondidos pelos assentados para a elaboração do PDA Canudos. Org. Melo, S. C. 2007.

Os dados, além de revelarem números, apontam também para as necessidades e demandas que um assentamento rural como Canudos passa a exigir. A proximidade com a capital, 33\% de seus moradores advindos da metrópole, outros 30\% também de origem urbana, conduz seus próprios moradores a estarem em constante vigilância sobre a condição do assentamento e dos assentados, tendo em vista que ali não se terá uma população com uma 'cultura' genuinamente rural, devido à proximidade do assentamento com a metrópole goiana e isso é algo que se revela na fala de alguns deles, ao serem questionados sobre esse tema.

O grau de compreensão de alguns assentados, e a apreciação que eles fazem de si e dos demais moradores de Canudos mostram o quanto é intensa as relações entre campo e cidade, presentes não só na territorialidade, mas também na vida, na cultura, nos valores, na economia, no cotidiano dessas pessoas. A instância campo-cidade em Canudos não se apresenta apenas pela proximidade com a RMG. Essa é uma característica ímpar nesse assentamento, especialmente no que se refere ao fluxo facilitado de informações, técnicas, serviços, comércio de produtos entre outros, que chegam nesse lugar, mas Canudos tem também em sua composição 29,56\% de pessoas que saíram de outras áreas urbanas do Estado.

O fato dos assentados em Canudos coexistirem com a experiência da cidade no campo, fora bastante observado e acompanhado ao longo da pes- 
quisa durante várias abordagens que realizamos com as famílias do assentamento, e com outros sujeitos que tiveram algum tipo de contato e/ou relação com Canudos e seus integrantes.

\section{Considerações finais}

Alegar que Canudos apresenta elementos da cidade no comportamento social dos seus sujeitos não é estar preso a uma leitura apenas da forma, até mesmo porque isso pode ser visualizado na fusão dos seus costumes e hábitos, tanto do campo como da cidade, especialmente na presença de alguns objetos deste ou daquele espaço. Ocorre que, no atual período técnico, entender o rural e o urbano não é algo que se restringe mais a uma cidade e seu campo imediato. As relações possuem uma amplitude maior e devem ser pensadas no conjunto da totalidade que as integra: na estrutura, na função, na forma e no conteúdo que se configura nessa espacialidade entendida como assentamento.

Apontar que a produção material e econômica, bem como o aspecto político responda que tipo de condição os assentados desenvolvem no lugar, limita a possibilidade de responder as indagações lançadas anteriormente, haja vista que também é necessário levar em conta a (re)produção subjetiva de suas vidas, e, se em Canudos, eles apenas não produzem uma condição de vida urbana, ao se associarem ao compasso rural por meio das técnicas e do trabalho, difundem assim, estreitos laços entre campo e cidade na territorialidade do assentamento.

\section{Nota}

1 Nesse trabalho procuramos analisar como um assentamento de reforma agrária relaciona-se com a cidade e da mesma forma como os vários elementos da cidade se fazem presente no assentamento, implicando assim na sua estrutura interna de produção e uso do solo, de hábitos, tradições, uso de instrumentos técnicos, assim como as relações de dependência que os assentados mantêm com a metrópole Goiânia, através de serviços, instituições diversas, mercado consumidor entre outros. 


\section{Referências}

ABRAMOVAY, R. Paradigmas do capitalismo agrário em questão. Campinas: Unicamp/Hucitec/ANPOCS, 1992.

. Funções e medida da ruralidade no desenvolvimento contemporâneo. IPEA, Texto para discussão $\mathrm{n}^{\circ}$ 762, 1998.

ALENTEJANO, P. R. R. As relações campo-cidade no Brasil do século XXI. Terra Livre, São Paulo, v. 2 n. 21, ano 19, jul/dez. 2003.

CARLOS, A. F. A questão da cidade e do campo. Teorias e políticas. Mercator, Fortaleza-CE, v. 5, p. 8-13, 2004

CHAYANOV, A. V. La organización de la unidad económica campesina. Buenos Aires: Nueva Visión,1985.

KAUTSKI, K. A questão agrária. Tradução de O. E. W. Maas. São Paulo: Nova Cultural,1980. (Os Economistas).

LENIN, V. I. A questão agrária. Tradução de C. F. de F. Casanovas. Rio de Janeiro: Calvino, 1945 .

. Que rural é esse? Uma reflexão sobre o significado do rural na sociedade capitalista. In: XIII Encontro Nacional de Geógrafos, 2002, João Pessoa. XIII Encontro Nacional de Geografia (caderno de resumos), 2002.

MOREIRA, R. O discurso do avesso. Rio de Janeiro: Dois Pontos, 1987.

. Cidade e campo no Brasil contemporâneo. Ciência Geográfica, Bauru, v. 11, n. 3, p. 193-199, 2005.

.O movimento operário e a questão cidade-campo no Brasil - Estudo sobre a sociedade e o espaço. Petrópolis: Vozes, 1985.

RODRIGUES. J. G. Estrutura agrária e produção familiar: a modernização da pecuária leiteira em São Luís de Montes Belos - GO. Goiânia, Descubra, 2003.

SANTOS, M. A urbanização brasileira. São Paulo, Hucitec, 1996.

. Pensando o espaço do homem. São Paulo, Hucitec, 1982.

SOJA, E. Geografias pós-modernas: a reafirmação do espaço na teoria social crítica. Rio de Janeiro: Zahar, 1993.

WILLIAMS, R. O campo e a cidade: na história e na literatura. Tradução de P. H. Britto. São Paulo: Cia das Letras. 1989.

Sandro Cristiano de Melo - Doutor pela Universidade Federal Fluminense e professor na rede municipal de ensino de Goiânia 